\title{
A INTERNACIONALIZAÇÃO DO ENSINO SUPERIOR: UM DESAFIO PARAAS UNIVERSIDADES
}

\author{
THE HIGHER EDUCATION INTERNATIONALIZATION: A \\ CHALLENGE FOR UNIVERSITIES
}

\begin{abstract}
LA INTERNACIONALIZACIÓN DE LA EDUCACIÓN SUPERIOR: UN DESAFÍO PARA LAS UNIVERSIDADES
\end{abstract}

Beatriz Maria Boéssio Atrib Zanchet ${ }^{1}$

Universidade Federal de Pelotas, Docente do Programa de Pós-graduação em Educação

Paula Trindade Selbach ${ }^{2}$

Universidade Federal do Pampa, Docente dos Cursos de Pedagogia e Letras

\section{Catia Simone Becker Vighi ${ }^{3}$}

Universidade Federal de Pelotas, Pesquisadora do Grupo de Pesquisa Democratização e internacionalização como desafio: a qualidade da educação superior no Brasil

Resumo: O interesse em compreender como as universidades vêm se movimentando na implantação do processo da internacionalização provocou a pesquisa em que se buscou compreender as concepções e ações presentes nos movimentos de duas universidades do Extremo-Sul do País. Procuramos evidenciar as aproximações e os distanciamentos entre elas a partir dos discursos sobre a implementação desse processo. Por meio da análise dos dados oriundos de seis entrevistas com gestores, percebemos que a concepção de internacionalização passa pela perspectiva dos acordos nacionais e internacionais, incluindo a participação de alunos em programas de mobilidade estudantil com expressivo interesse dos gestores em relação ao significado desse processo mais amplo de internacionalização no contexto do ensino superior. Houve destaque ao estabelecimento de cooperação no contexto "sulino" e ao desenvolvimento regional como resultado da internacionalização. Concluímos que a compreensão dessa com-

\footnotetext{
${ }^{1}$ Pós-doutora e Doutora em Educação pela Universidade do Vale do Rio dos Sinos; Mestre em Educação pela Universidade Federal de Santa Maria.

${ }^{2}$ Doutora em Educação pela Universidade Federal do Rio Grande do Sul; Mestre em Educação pela Universidade Federal de Pelotas.

${ }^{3}$ Doutora e Mestre em Educação pela Universidade Federal de Pelotas.
} 
plexa temática é frágil no contexto das universidades pesquisadas e que há forte indício da necessidade de potencializar mais ações no sentido da internacionalização.

Palavras-chave: Internacionalização. Ensino superior. Gestão universitária.

\begin{abstract}
The interest in understanding how universities are moving in the implementation of the internationalization process, led ti research that sought to understand the conceptions and actions present in the movements of two universities in the extreme south of the country. We try to show the approximations and distances between them from the discourses on the implementation of this process. Through the analysis of data from six interviews with managers, we see that the conception of internationalization passes through the perspective of national and international agreements, including the participation of students in student mobility programs with expressive interest of the managers in relation to the meaning of this broader process Internationalization in the context of higher education. The establishment of cooperation in the "southern" context and regional development as a result of internationalization was emphasized. We conclude that the understanding of this complex theme is fragile in the context of the researched universities and that there is strong evidence of the need to potentiate more actions towards internationalization.
\end{abstract}

Keywords: Internationalization. Higher education. University management.

Resumen: El interés en comprender cómo las universidades vienen moviéndose en la implantación del proceso de la internacionalización, provocó la investigación que buscó comprender las concepciones y acciones presentes en los movimientos de dos Universidades del extremo sur del país. Se trata de evidenciar las aproximaciones y distanciamientos entre ellas a partir de los discursos sobre la implementación de ese proceso. A través del análisis de los datos provenientes de seis entrevistas con gestores, percibimos que la concepción de internacionalización pasa por la perspectiva de los acuerdos nacionales e internacionales, incluyendo la participación de alumnos en programas de movilidad estudiantil con expresivo interés de los gestores en relación al significado de ese proceso más amplio De internacionalización en el contexto de la enseñanza superior. Se ha destacado el establecimiento de cooperación en el contexto "sureño" y el desarrollo regional como resultado de la internacionalización. Concluimos que la comprensión de esta compleja temática es frágil en el contexto de las Universidades investigadas y que hay un fuerte indicio de la necesidad de potenciar más acciones en el sentido de la internacionalización.

Palabras clave: Internacionalización. Enseñanza superior. Gestión universitaria. 


\section{INTRODUÇÃO}

As transformações na esfera da economia das instituições sociais, culturais e políticas, que ocorrem desde os anos 1990, encontram-se inseridas no processo da crescente globalização da economia e da reestruturação da divisão internacional do trabalho, da desregulamentação dos mercados e da redefinição da estrutura e papel dos Estados nacionais.

O discurso que coloca o conhecimento como uma das principais variáveis na explicação das formas de organização social e econômica provoca a discussão em torno do lugar da educação nas políticas públicas. O conhecimento é considerado um dos principais condicionantes do desenvolvimento, gerando novas desigualdades entre os países. A educação cresce em importância diante do ambiente de competitividade que se instala e se torna, assim, elemento central nos discursos e nas políticas, sendo considerada uma das condições fundamentais para os países atingirem melhor posição no cenário mundial. A competitividade e a produtividade incorporam-se às políticas educativas como valores fundamentais.

Como explica Seixas (2001), a globalização econômica aumenta a competição internacional e a necessidade de investir em novas tecnologias. O papel do ensino superior, nesse contexto, torna-se crucial, exigindo-se dele a descoberta de novos produtos e processos necessários para manter a posição nacional na economia mundial.

Considerando que a universidade sempre foi uma instituição global (ALTBACH, 1998), o processo de globalização reforça a internacionalização dos sistemas educativos, sendo este um dos elementos que compõem a esfera de relações estabelecidas dentro dessa instituição desde sua estrutura medieval de criação, partindo da ideia da ampliação de suas fronteiras, com a mobilidade de alunos e professores, objetivando atender às necessidades que surgiam mediante o avanço para o mundo moderno. Como afirma Knight (2004, p. 5), a “internacionalização está mudando o mundo do ensino superior e a globalização está mudando o mundo da internacionalização."

O contínuo crescimento da internacionalização dos sistemas educativos e a similaridade existente entre as reformas educativas implementadas por diversos países fomenta o debate sobre as diretrizes que tem se sobressaído na promoção da internacionalização e acerca das reais intenções do fenômeno sobre o ensino superior.

$\mathrm{Na}$ perspectiva da implementação da internacionalização, algumas universidades propuseram-se a discutir seus projetos político-pedagógicos e a delinear seus planos de desenvolvimento institucional em sintonia com as transformações sociais e seus reflexos no ensino superior. Entre essas universidades, tomamos duas univer- 
sidades federais situadas no Sul do País - uma delas localiza-se no Extremo-Sul, denominada neste texto de Ua, e a outra em uma região de fronteira, nomeada de Ub - que estão incorporando e implementando programas governamentais de expansão e internacionalização do ensino superior. Cabe salientar que a Ua é uma Instituição consolidada com abrangência na região e reconhecida em nível nacional, que se tornou universidade e foi federalizada nos anos 1960. A Ub é uma Instituição criada no contexto da expansão e interiorização da educação superior no ano 2006, sendo considerada uma Universidade em processo de consolidação e ampliação.

Refletir sobre o movimento dessas Instituições no contexto da implementação do processo de internacionalização foi o objetivo com a pesquisa que realizamos. Buscamos, com ela, compreender as concepções e ações presentes nos movimentos dessas duas Universidades do Extremo-Sul do País, procurando evidenciar as aproximações e os distanciamentos entre elas a partir dos discursos que configuram as estratégias de implementação desse processo.

A pesquisa qualitativa contou com seis colaboradores - que estavam na gestão das Universidades e eram responsáveis, direta ou indiretamente, pela implementação de ações de internacionalização - os quais responderam a uma entrevista semiestruturada realizada no seu local de trabalho durante o período de maio de 2014 a maio de 2015. As entrevistas versaram sobre o posicionamento da Instituição em relação à internacionalização, participação da Universidade nesse processo, ações, desdobramentos e desafios no contexto da graduação e interferência na qualidade do ensino. As entrevistas foram gravadas e posteriormente transcritas. Os participantes assinaram o termo de consentimento livre e esclarecido garantindo a participação voluntária e o anonimato dos respondentes. Os dados obtidos tiveram seu conteúdo analisado à luz dos estudos de Knight (2004, 2011, 2014) e Morosini (2006, 2011), entre outros autores.

Neste texto apresentamos inicialmente uma discussão sobre os diferentes conceitos de internacionalização, alertando para alguns mitos que circundam esse processo e, posteriormente, referimo-nos aos dados analisados que constituem a pesquisa realizada.

\section{INTERNACIONALIZAÇÃO: VISLUMBRANDO ALGUNS CONCEITOS}

A internacionalização não é um fenômeno novo em se tratando de educação superior, mas ganha proporções muito particulares em momentos nos quais esse nível de ensino tem sua função problematizada. 
Compreendemos que a internacionalização da educação superior se pauta em uma ordem global que compreende novas formas de relação entre países e instituições, provocando discussões sobre os processos de globalização e de internacionalização propriamente dita. Altbach (2004) afirma que existe proximidade desses processos e explica que globalização é uma realidade do século XXI conformada pela economia mundial, integrada pelas tecnologias de comunicação e informação e pelo surgimento de uma rede internacional do conhecimento. Salienta que a internacionalização é definida como a variedade de políticas e programas que as universidades e os governos implementam para responder à globalização.

Em relação à globalização, podemos assinalar que, como defende Sousa Santos (2011, p. 20), este "é um vasto e intenso campo de conflitos entre grupos sociais" e repercute prontamente na política educacional, com toda a complexidade. Inclusive, esses conflitos não se encerram no campo da produção de políticas a partir das decisões colocadas nos textos oficiais, mas seguem no interior das instituições, estão expressos nas relações cotidianas dos seus diferentes atores, mesmo os que não atuam diretamente nelas. O mesmo autor explica, ainda, que estudos sobre os processos de globalização "mostram-nos que estamos perante um fenômeno multifacetado com dimensões econômicas, sociais, políticas, culturais, religiosas e jurídicas interligadas de modo complexo." (SOUSA SANTOS, 2011, p. 1). Afirma que a forte tendência em reduzir esse fenômeno às questões financeiras obscurece outras relações igualmente importantes entre a dimensão social, política e cultural, e que as características gerais da globalização podem levar à falsa ideia de que esses processos são produzidos linearmente.

Alguns autores têm procurado verificar e explicar os efeitos que a globalização tem proporcionado ao ensino superior e sinalizam que, muitas vezes, tais efeitos acontecem em larga escala e também apresentam ambiguidade, pois podem ser tanto negativos quanto positivos. Vaira (2004) aponta que os efeitos apresentam caráter de homogeneização das instituições e têm repercussões nas macroestruturas, além de serem relacionados aos microssistemas, uma vez que tais elementos são responsáveis pelas mudanças em nível global.

Um conceito de internacionalização que temos considerado é o apresentado por Knight (2014, p. 1), que diz que esse "é o processo de integração de uma dimensão global, intercultural e global nos objetivos, ensino, aprendizagem, pesquisa e serviços de uma universidade ou de um sistema de ensino superior." Dessa forma, a internacionalização está transformando o mundo da educação superior, e a globalização está transformando o mundo da internacionalização, conforme dito anteriormente. Cabe salientar que o termo processo é utilizado por Knight para explicitar que 
a internacionalização ocorre por meio de um esforço contínuo; o próprio conceito de internacionalização está em permanente evolução.

Em relação à internacionalização da educação superior, Morosini (2006) explica que esta se caracteriza como um conceito complexo, com uma diversidade de termos relacionados, apresentando diversas fases de desenvolvimento. Diz a autora que, de um modo geral, os conceitos podem ser agrupados em três grandes eixos: a) dimensão internacional - que está relacionada aos aspectos mais incidentais, em razão de que o termo acabou se disseminando sem uma organização, mais precisamente no século XX; b) educação internacional - caracterizada pelos relacionamentos estabelecidos pelos EUA, entre a Segunda Guerra Mundial e a Guerra Fria, segundo razões políticas e econômicas; c) internacionalização da educação superior - surgida após a guerra fria, possuindo características estratégicas relacionadas à globalização e uma "regionalização" das sociedades.

Também Bartell (2003) conceitua a internacionalização como "trocas internacionais relacionadas à educação", e a globalização como uma avançada fase no processo que envolve a internacionalização. $\mathrm{O}$ autor apresenta em seus estudos as alternativas para se concretizar o processo de internacionalização, como, por exemplo, presença de estrangeiros e estudantes-convênios em um determinado campus; número de concessões de pesquisas internacionais; projetos de pesquisas internacionais cooperativos; associações envolvendo consultoria para universidades estrangeiras; grau de imersão internacional no currículo, entre outros.

De outro modo, para Teichler (2004), a internacionalização caracteriza-se por crescentes atividades além-fronteiras entre os sistemas nacionais de educação superior, sendo que esse processo está perdendo espaço para a globalização. Explica o autor que a globalização é caracterizada por atividades ambíguas, além-fronteiras, e é empregada com frequência para caracterizar as tendências mundiais e a crescente competição global.

Como é possível compreender, além de se apresentar como um termo polissêmico sobre o qual não há consenso conceitual, o processo de internacionalização traz em seu bojo uma série de questionamentos e mitos recorrentes.

\section{OS MITOS SOBRE INTERNACIONALIZAÇÃO DO ENSINO SUPERIOR EM DESTAQUE}

Knight (2014) explica que o processo de internacionalização de uma IES tem uma relação bastante estreita com a sua colocação nos rankings internacionais e 
regionais. Esse aspecto figura com destaque em um conjunto de mitos que circunda o processo de internacionalização.

Os mitos apresentados por Knight (2011) questionam a ideia do papel desempenhado pelos estudantes estrangeiros enquanto agentes da internacionalização, a ideia da internacionalização como indicador da qualidade, os acordos institucionais, a certificação internacional como indicadores do nível de internacionalização e a internacionalização enquanto estratégia para atingir posições elevadas nos rankings das instituições de ensino superior.

No primeiro mito, Knight (2011) afirma que é antiga a crença que a quantidade de estudantes estrangeiros nos campi universitários influencia a produção de uma cultura e de um currículo mais internacionalizado. Intitula esse mito como estudantes estrangeiros como agentes da internacionalização e nele explica que, mesmo que a expectativa das universidades seja a de ter uma cultura e um currículo mais internacionalizados a partir do maior número de estudantes estrangeiros, não é isso o que a realidade está mostrando. É frequente o entendimento de que, a partir da integração de alunos estrangeiros nos diversos cursos de uma universidade, possa haver a produção de uma cultura mais internacionalizada.

No entanto, os estudantes estrangeiros não são integrados de fato, ou seja, Knight (2011) explica que em muitas instituições eles se sentem marginalizados, tanto social quanto academicamente e, em alguns casos, experimentam também tensões étnicas ou raciais. Observa que os estudantes locais são conhecidos por resistirem ou serem neutros em relação à realização de projetos acadêmicos conjuntos ou a se engajarem socialmente com os estudantes estrangeiros, a menos que um programa específico seja desenvolvido pela instituição. O que por vezes acontece é a união dos estrangeiros entre si, o que os ajuda a ter uma experiência intercultural mais ampla e significativa. Logo, dizer que a primeira razão para recrutar estudantes estrangeiros é a possibilidade de internacionalização do campus mascara outros motivos mais significativos, como a geração de receita ou a melhoria da posição da instituição no ranking global, como explica a autora.

No segundo mito, reputação internacional como indicador da qualidade, Knight (2011) explicita a crença de que se acredita que quanto mais internacional seja uma universidade em termos de professores, pesquisa e currículo, melhor é sua reputação. Entretanto, essa ideia está ligada à falsa noção de que a forte reputação internacional é um indicador para a qualidade. Explica que casos de padrões questionáveis de admissão e de saída por universidades altamente dependentes da receita e do valor da marca são evidências que a internacionalização nem sempre se traduz em qualidade. 
É altamente questionável se as tabelas classificativas das universidades medem com precisão a internacionalidade de uma instituição e, mais importante, se a dimensão internacional é sempre um indicador "robusto" da qualidade.

No mito de número três, acordos institucionais internacionais, Knight (2011) alerta que, muitas vezes, crê-se que o maior número de acordos ou de redes e afiliações internacionais que uma universidade tem a torna mais prestigiada e atraente para outras instituições e estudantes. No entanto, segundo a autora, a prática mostra que a maioria das instituições não pode gerenciar ou, até mesmo, se beneficiar de uma centena de acordos, pois para os manter é necessário maior investimento em recursos humanos e financeiros. Nesse caso, a quantidade é vista como mais importante do que a qualidade, e a lista de acordos internacionais é usada principalmente como símbolo de status do que um registro de colaborações acadêmicas efetivas. $\mathrm{O}$ enxugamento do número de acordos, feito de cima para baixo (top-down), é uma tendência atual e pode levar a uma relação mais abrangente e sustentável entre os envolvidos, embora os professores e pesquisadores fiquem descontentes por terem diminuídas suas verbas para pesquisa.

A premissa de que quanto mais créditos das agências internacionais para uma universidade, melhor seria a qualidade nacional é o quarto mito, que a autora intitula acreditação internacional. Para Knight (2011), a premissa é questionável, pois alerta que o reconhecimento estrangeiro da qualidade não faz menção aos valores, às escalas relativas aos processos de ensino e de aprendizagem, à pesquisa e aos serviços à sociedade.

Em relação ao quinto mito, marca global, a autora explora a presunção incorreta de que o propósito de esforços da internacionalização de uma universidade é melhorar sua marca/posição global. Diz ela que existe certa confusão entre marketing internacional e plano de internacionalização das universidades. Observa que o marketing é um exercício de promoção da marca institucional, e o plano de internacionalização é uma estratégia para integrar as dimensões internacional, intercultural e global aos objetivos do ensino, da pesquisa e dos serviços da universidade. Salienta, inclusive, que os objetivos, os resultados antecipados e os investimentos em iniciativas de marca global são diferentes daqueles exigidos para a internacionalização acadêmica. Logo, ratifica que é um mito que o esquema de marketing internacional é equivalente ao plano de internacionalização. Interessante dizer que a autora não nega que uma agenda de internacionalização estratégica e bem-sucedida leve a uma visibilidade internacional, mas salienta que esse não é o objetivo, mas, sim, um subproduto.

Por fim, Knight (2011) explica que um elemento comum em muitos desses mitos é que os benefícios da internacionalização ou o grau de cooperação internacional pode ser medido quantitativamente - número de estudantes internacionais, profes- 
sores estrangeiros, acordos institucionais, projetos de pesquisa, etc. Entretanto, alerta que, embora a tentativa de quantificar os resultados sirvam como indicadores-chave de desempenho e da prestação de contas, eles não captam/capturam os principais fatores humanos (performance) de alunos, professores e da comunidade que trazem benefícios significativos da internacionalização.

Os mitos trazidos pela autora são pertinentes e acreditamos que, ao estarem na pauta das discussões, facilitam o diálogo com os processos de internacionalização da educação superior.

\section{O PROCESSO DE INTERNACIONALIZAÇÃO EM DUAS UNIVERSIDADES: APROXIMAÇÕES E DISTANCIAMENTOS}

A internacionalização do ensino superior tem sido enfatizada como um importante processo que ajuda a universidade a formar pessoas e profissionais para um mundo complexo e globalizado. Essa ênfase está exigindo um cuidado especial por parte dos gestores das universidades, pois se trata de um processo amplo que precisa ser planejado dentro de uma política institucional de desenvolvimento.

Em diálogo com os interlocutores deste estudo, foi possível perceber que esse processo precisa estar na pauta das discussões do projeto institucional, pois, sendo importante e desafiador, precisa ser tratado de forma aprofundada e com contínuas reflexões sobre sua amplitude e significado no contexto das universidades.

Essa perspectiva se revela na menção de um interlocutor da Ua quando afirmou que

no plano de desenvolvimento da Instituição (PDI) ela [a internacionalização] não está colocada totalmente como uma política institucional que tem " $n$ " ramificações para diversas áreas, $[. .$.$] porque esta questão da internacionalização é um pro-$ blema muito sério para nós, especialmente; para nós não, para todas as universidades. (informação verbal).

Por outro lado, a respondente da Ub faz um relato referente ao processo de construção de um novo PDI da universidade. Esse momento favoreceu que os processos de internacionalização fossem repensados

A gente, por exemplo, pensou no trabalho de inserção da internacionalização dentro do PDI, pois não existia quase nada. Então, ali dentro a gente colocou todas as necessidades da assessoria, e aí colocamos um plano estratégico com metas [...] quais os objetivos alcançados, para ter uma leitura, até 2018. (informação verbal). 
Conforme explica Knight (2004), repensar os objetivos leva a repensar o papel da universidade em determinada região, articulando com a missão da universidade, e esta tem sido uma preocupação da Ub.

Vislumbrar o processo de internacionalização no projeto institucional foi uma estratégia da primeira gestão da $\mathrm{Ub}$.

Esse fator da internacionalização já era um elemento que estava presente desde o início da criação da Universidade [...] já tinham sido colocadas duas tradutoras de espanhol e de inglês na reitoria, em vista justamente da criação desta assessoria. E aí juntou o fato da criação do curso de relações internacionais. (informação verbal).

É interessante considerar que esses dois movimentos, um oriundo da Ua e outro da Ub, representam estágios distintos no processo de internacionalização dessas instituições, o que pode estar intimamente relacionado com o fato de a Ub ter sido criada em um contexto temporal que estimulava o processo de internacionalização, enquanto a Ua buscava alternativas para se enquadrar na demanda proposta de internacionalização, considerando também sua condição de ser "periférica", em razão da sua localização geográfica no País.

Há constante ênfase nas respostas dos gestores que internacionalizar seja uma preocupação institucional e que seja visível à comunidade acadêmica. Não basta apenas atender à demanda, é preciso estar atento às estratégias para a internacionalização acontecer na instituição como um todo. Internacionalizar passou a ser uma condição importante na qual a instituição precisa investir e divulgar.

É importante alertar que o processo de internacionalização está além do trânsito de alunos. É um processo que precisa envolver a comunidade e se estabelecer como uma política institucional. Nas respostas destacamos que há preocupação em fazer acontecer a internacionalização em sentido mais ampliado.

Eu acho que seria muito [...] muito importante a universidade ter uma política institucional voltada à internacionalização, ou seja, que não seja só uma reação às demandas que a gente recebe, mas que dentro da política institucional, por exemplo, dentro do orçamento tenha uma rubrica que seja de internacionalização. (Ub, informação verbal).

Como observado, no processo de internacionalização existem outros fatores que estão imbricados, ou seja, a internacionalização ultrapassa o tema educação e circulação de pessoas e conhecimento. Deve-se considerar que esse processo pode 
estar intimamente relacionado com questões econômicas que, por sua vez, percebem na universidade um instrumento catalisador para essa dinâmica, de maneira que é preciso a universidade estar preparada para participar e ir além, salientando sua real função no desenvolvimento da sociedade.

A descoberta de produtos e a geração de conhecimentos que ajude a sociedade a alcançar melhor posição no cenário nacional e internacional, são motivos que levam o ensino superior a assumir uma posição de destaque no processo de internacionalização dos países.

É importante que a universidade esteja preparada para a implementação do processo de internacionalização e não apenas estimule a participação e o envolvimento das pessoas sem oferecer as condições para que aconteça de forma intensa e planejada. Dessa feita, observa-se que não basta a participação tácita das universidades em programas implementados por Estados interessados em estimular a troca de experiências e conhecimentos entre os acadêmicos. É preciso que a universidade, por meio de seus gestores e da comunidade acadêmica, esteja ciente do que se trata e quais os objetivos da internacionalização, não se tornando apenas executora de um projeto com pouco sentido e significado para os envolvidos.

Parece fundamental fomentar uma discussão sobre o significado e o conceito de internacionalização para que ocorra a organização e a adequação institucional, criando condições e possibilidades para a implementação de programas, parcerias e para o trato com a comunidade acadêmica durante o processo.

Entendemos que a implementação de parcerias pode contar com a contribuição efetiva de alunos e professores da instituição que tenham participado de outros movimentos com o propósito de internacionalização. Suas contribuições se tornam instrumentos importantes para tornar pública sua experiência e socializar com outros discentes e docentes, inclusive aqueles que futuramente desejem participar de processos dessa natureza. Ao mesmo tempo, é uma oportunidade significativa para refletir sobre possíveis adequações e reformulações no intuito de aperfeiçoar o processo de internacionalização dentro de cada contexto universitário.

Pensar o que é internacionalização do ensino superior é muito importante no contexto de discussão das estratégias de sua implantação, visto que ela pode assumir diferentes perspectivas e distintas visões sobre o processo. Nesse sentido, Oliveira e Morosini (2012) salientam que os conceitos de internacionalização oscilam entre duas visões distintas. Sobre a perspectiva de convênios, acordos e mobilidade acadêmica trata-se, muitas vezes, de uma visão minimalista ou estática. Por outro lado, as autoras advertem que a visão complexa e abrangente da internacionalização está 
relacionada à orientação de políticas que permeiam a vida, as atividades de ensino e pesquisa da universidade e de seus membros.

As respostas mostraram que o entendimento desse processo é necessário.

$\mathrm{Na} \mathrm{Ua}$

[...] essa ideia de internacionalização não pode significar descolamento do nosso espaço, quer dizer, nós nos enriquecemos com esse processo para que a Instituição tenha condições de agir no meio onde está inserida. Eu pessoalmente, eu não acredito que uma instituição possa ter um grande reconhecimento internacional se ela não tiver a possibilidade de responder à sua realidade. Então acho que isso é uma coisa de se pensar. (informação verbal).

Interessante perceber que essa perspectiva vai ao encontro do que explica Knight (2014, p. 5) quando diz que

[...] a internacionalização se reconhece e se baseia em prioridades, políticas e práticas locais, nacionais e regionais. A internacionalização visa complementar, harmonizar e ampliar a dimensão local, não dominá-la. Se esta verdade fundamental não é respeitada, há forte possibilidade de retrocesso e da internacionalização ser vista como um agente de homogeneização ou hegemônico. Honrar a construção da cultura e o contexto local é um princípio fundamental da internacionalização.

A ênfase no reconhecimento do papel regional da Ua foi ratificada quando um entrevistado afirmou que "é indispensável para uma instituição universitária, trabalhar em uma perspectiva de integração solidária, internacional, para que a gente possa fazer com que haja um reconhecimento e que nós tenhamos uma vocação que é regional." (informação verbal).

O reconhecimento local e regional de uma universidade é fator a ser considerado quando se fala em internacionalização. Knight (2014) explica que esse processo é impulsionado por uma avaliação das necessidades e prioridades individuais das instituições. No caso das universidades deste estudo, em razão das suas localizações geográficas e de suas performances em nível regional, torna-se fundamental pensar a internacionalização valorizando o próprio contexto de atuação e vinculando esse processo aos propósitos social e acadêmico que as sustentam.

Gacel-Ávila (1999) trata do processo de internacionalização como uma abertura institucional para o exterior e salienta a importância de tal processo ser parte dos planos de desenvolvimento das instituições de ensino superior (IES), principalmente porque essa perspectiva se configura, para a instituição, como uma estratégia de desenvolvimento de uma nova cultura com enfoque internacional, intercultural 
e interdisciplinar, aproximando-se de ações de interação e cooperação institucional. Interessante é perceber que o envolvimento das Universidades com o crescimento do espaço onde estão inseridas é fato considerado, também pelos grupos gestores, como importante no processo de internacionalização.

Embora seja relativamente recente a discussão da internacionalização nas Universidades analisadas, percebe-se que existe, por parte das gestões, preocupação na elaboração de estratégias para implementar esse processo, sem deixar de considerar sua posição no contexto local e regional. Nessa perspectiva, internacionalização é um processo em movimento que ultrapassa a realização de atividades no âmbito internacional e que considera o contexto nacional como foco.

Foi observado que algumas razões para internacionalizar apontadas por Knight (2004) aparecem, de alguma forma, expressas nas respostas dos gestores entrevistados, mesmo que nem sempre de forma explícita. Em relação às alianças estratégicas, por exemplo, foi-nos relatado por um interlocutor da Ua que o reitor está se empenhando em buscar novas parcerias para a Universidade. "Tem encontros de reitores latino-americanos, dos países de língua portuguesa e tem esses grupos, o grupo Coimbra e outros. Na universidade esta é a política; é participar de tudo que puder. E a ideia é que essas viagens repercutam em alguma ação." (informação verbal).

Entendemos que as parcerias dentro do contexto "sulino" seriam a forma de alcançar, bem como o desenvolvimento regional perante a formação qualificada dos profissionais, uma maneira de competir no mercado que é cada vez mais seletivo, além de promover o desenvolvimento de cada país envolvido a partir dos acordos de cooperação firmados.

Não é possível negar que existe forte influência no sentido de a internacionalização acontecer no sentido Sul-Norte. Em geral, as ações de mobilidade discente e docente e de pesquisadores que buscam ampliar e gerar novos conhecimentos científicos têm efetivado um fluxo predominantemente com deslocamento nessa direção.

Mas, as Universidades pesquisadas precisam olhar para a América Latina como possibilidade de internacionalização. A Ua expressou que

[...] um vínculo que aí extrapola os objetivos da Capes é a ideia de uma relação mais sul-sul. Nós viramos as costas para a América Latina, como se ela não existisse. Nós só olhamos para o norte ou para a Europa e têm relações muito interessantes aqui na América Latina, Argentina, Chile e todos os demais países. (informação verbal).

Em contrapartida, na Ub a ênfase é de um trânsito com países do Norte. "A gente também já tem convênios com várias outras universidades da Europa, especi- 
ficamente Portugal, Espanha. Nós temos Canadá e temos alguns específicos também dos Estados Unidos." (informação verbal).

Considerando que essas Instituições se localizam em contexto de fronteira, pareceria natural um olhar preferencial para os países vizinhos. Mas não é o que acontece; talvez também por responsabilidade dos órgãos centrais de fomento que apenas há pouco tempo propuseram alguns programas de cooperação com países latino-americanos.

Cabe salientar que, mesmo enfatizando os diversos acordos e convênios internacionais, os entrevistados não remeteram essa condição à promoção da marca global da Universidade. Os esforços para expandir e manter os acordos parecem fazer parte do plano de internacionalização das IES pesquisadas, e, nesse sentido, não observamos que o plano de internacionalização se confunda com o marketing internacional, como alerta Knight (2011), ao discutir os mitos da internacionalização.

Foi possível perceber que a visão de qualidade da Universidade incluí o número de acordos firmados, principalmente se forem acordos internacionais e participações em redes. Essa condição é preocupante se considerarmos a forte influência da visão mercadológica sobre o ensino superior. Cabe perguntar: tornar-se-á a universidade mais submissa à lógica de mercado para garantir maior quantidade de acordos e/ou parcerias internacionais? Essa é uma das questões que exige respostas e que certamente implica a qualidade do ensino.

Ao referir-se ao mito dos acordos institucionais internacionais como indicador da internacionalização, Knight (2011) reforça, mais uma vez, que a quantidade é vista como mais importante do que a qualidade, e que a lista de acordos internacionais é usada como um símbolo de status mais que como um registro de colaborações acadêmicas funcionais. Para a autora, é inevitável o enxugamento do número de acordos, pois a universidade não pode gerenciar ou até mesmo se beneficiar de uma centena de acordos, pois, para os manter, é necessário maior investimento em recursos humanos e financeiros. Assim, explica Knight (2011, p. 2, tradução nossa): “[...] a longa lista de parceiros internacionais reflete muitas vezes acordos baseados apenas em papel [...]"4

Nesse contexto, Castro e Neto (2012) explicam que há uma mudança substancial no conceito de cooperação internacional. Inicialmente a ideia era que a cooperação se constituía uma fonte de financiamento externa; entretanto, hoje, assume uma característica mais ampliada. A cooperação deve se converter em um instrumento para a internacionalização dos sistemas de educação superior com políticas mais ativas, incluindo temáticas e prioridades regionais.

\footnotetext{
4 “[...] the long list of international partners often reflects paper-based agreements [...]" (KNIGHT, 2011, p. 2).
} 
Perceber a internacionalização como um processo de grande amplitude que abrange políticas institucionais, cooperação internacional, mobilidade de estudantes e professores, franquia de cursos, pesquisas internacionais, entre outros, provoca demandas e movimentos das universidades ao mesmo tempo em que exige alterações internas na sua organização para atender às novas exigências do processo. Para o interlocutor da Ua: “[...] a ideia de que a universidade, essa integração internacional, ela é capaz de fazer com que haja uma espécie de desalojar interno e que as coisas fiquem muito mais dinâmicas internamente." (informação verbal).

Foi possível perceber que existe preocupação por parte da gestão entrevistada em mobilizar seus integrantes para a implementação da internacionalização como um valor, mesmo que, às vezes, essa não seja uma tarefa fácil, constituindo-se em um grande desafio.

As Universidades estudadas mencionam outros impasses dentro do processo de internacionalização ligados à mobilidade estudantil, como, por exemplo, o currículo. Foi expressa como preocupação por todos os entrevistados a correspondência de disciplinas cursadas em outra IES com as disciplinas do curso em desenvolvimento pelo estudante. Essa é uma questão que merece atenção. Como lembra Seixas (2001, p. 214), "a crescente mobilidade dos estudantes contribui não só para a crescente internacionalização dos sistemas educativos como para o desenvolvimento de mercados internacionais de ensino superior." Continua a autora explicando que

Os programas comunitários desenvolvidos pela União Europeia visando favorecer a mobilidade dos estudantes promovem uma internacionalização dos currículos na medida em que implicam a elaboração de planos de transferência de unidades capitalizáveis a nível europeu, visando o reconhecimento e validação dos períodos passados em instituições de ensino superior estrangeiras. (SEIXAS, 2001, p. 2140).

Reflexões no sentido apontado pela autora estão presentes nas respostas dos gestores entrevistados. Na Ua há a compreensão de que

[...] o problema que estamos enfrentando agora é que os alunos retornam e os cursos não tem correspondência de disciplinas. Valida-se com que? Será que a experiência lá não foi importante? Ah, mas não tem a disciplina tal, que ele fez lá. Bom, põe como optativa! Esse é um problema que a gente vai ter que enfrentar agora. Já estamos enfrentando. (informação verbal).

Eles também enfatizaram a ideia de flexibilização do currículo no contexto da Ub

A ideia do que é que é um currículo em termos de flexibilização, como é que é pensar esse currículo não fechado e formatado. 
Será que é só aquilo que está ali? Temos que observar normativas, diretrizes curriculares, aspectos normativos da instituição, nós temos que abrir também essas possibilidades, e é um enriquecimento. (informação verbal).

O que se evidencia e se alerta nas questões que envolvem o currículo é que é possível pensar em alternativas diversas para a incorporação das experiências vividas em outra IES no currículo do aluno, desde que estas respondam à realidade e ao contexto e que nele sejam significativas. Os alunos "aprendem" com outras experiências; todavia é preciso ter cuidado com as transferências lineares. O mais interessante seria trabalhar com a pluralidade e não em uma perspectiva de nivelamento e uniformidade, uma vez que entre os propósitos da internacionalização está a troca de experiências e, por consequência, o crescimento cultural, pessoal, etc. Essa parece ser também a preocupação das gestões das Universidades aqui estudadas.

Acompanhar o movimento dos alunos e dos professores em torno da discussão sobre o currículo pode ser uma estratégia que valoriza os protagonistas das experiências, além de ampliar a possibilidade de impacto dos processos vividos em outras realidades educacionais nos currículos universitários.

No sentido de organização e em um esforço de síntese dos achados, definimos quatro dimensões que orientaram a articulação dos dados: estratégias para implantação do processo de internacionalização, internacionalização e perspectivas de qualidade, desafios enfrentados e ações empreendidas, cotejando aproximações e distanciamentos entre as duas Universidades estudadas.

Quadro 1 - Aproximações e distanciamentos entre as Instituições

\begin{tabular}{|c|c|c|c|}
\hline & \multirow{2}{*}{ Aproximações } & \multicolumn{2}{|l|}{ Distanciamentos } \\
\hline & & $\mathrm{Ua}$ & $\mathrm{Ub}$ \\
\hline Estratégias & $\begin{array}{l}\text { Criação de coordenadoria } \\
\text { para tratar de assuntos } \\
\text { ligados às relações inter- } \\
\text { nacionais. }\end{array}$ & $\begin{array}{l}\text { Ainda em discussão a } \\
\text { inclusão da inter- } \\
\text { nacionalização no } \\
\text { PDI como política } \\
\text { institucional. }\end{array}$ & $\begin{array}{l}\text { Internacionalização já } \\
\text { incluída no PDI como } \\
\text { política institucional. }\end{array}$ \\
\hline $\begin{array}{l}\text { Internacionaliza- } \\
\text { ção e qualidade }\end{array}$ & $\begin{array}{l}\text { Atendimento a demandas } \\
\text { regionais como indicador } \\
\text { de qualidade; } \\
\text { Melhoria do espaço onde } \\
\text { estão inseridas. }\end{array}$ & $\begin{array}{l}\text { Destaque para possibi- } \\
\text { lidade de acordos com } \\
\text { a América Latina; } \\
\text { Crescimento da Uni- } \\
\text { versidade com ênfase } \\
\text { na inserção regional. }\end{array}$ & $\begin{array}{l}\text { Quantidade de acordos } \\
\text { é tomada como indica- } \\
\text { dor de qualidade, com } \\
\text { destaque aos acordos } \\
\text { com EUA e Europa; } \\
\text { Projeção da Universi- } \\
\text { dade em nível nacio- } \\
\text { nal e internacional. }\end{array}$ \\
\hline
\end{tabular}




\begin{tabular}{|c|c|c|c|}
\hline Desafios & $\begin{array}{l}\text { Incentivar a comunidade } \\
\text { acadêmica (professores } \\
\text { em especial) a participar } \\
\text { de ações na direção da } \\
\text { internacionalização; } \\
\text { Flexibilizar o currícu- } \\
\text { lo para incorporar as } \\
\text { “experiências" vividas em } \\
\text { outro lugar (disciplinas } \\
\text { cursadas). }\end{array}$ & $\begin{array}{l}\text { Infraestrutura básica } \\
\text { para atender as de- } \\
\text { mandas da internacio- } \\
\text { nalização. }\end{array}$ & $\begin{array}{l}\text { Visibilidade da Uni- } \\
\text { versidade no cenário } \\
\text { nacional e interna- } \\
\text { cional. }\end{array}$ \\
\hline Ações & $\begin{array}{l}\text { Adesão aos programas de } \\
\text { mobilidade estudantil; } \\
\text { Incentivar a participação } \\
\text { da comunidade acadêmica } \\
\text { em parcerias internacio- } \\
\text { nais. }\end{array}$ & $\begin{array}{l}\text { Poucos espaços } \\
\text { definidos e incentivos } \\
\text { para os alunos sociali- } \\
\text { zarem as experiências; } \\
\text { Aumento do fluxo } \\
\text { de docentes e de } \\
\text { pesquisas em nível } \\
\text { internacional. }\end{array}$ & $\begin{array}{l}\text { Incentivar os espaços } \\
\text { definidos para os } \\
\text { alunos socializarem } \\
\text { as experiências inter- } \\
\text { nacionais; } \\
\text { Aumento do número } \\
\text { de participação em re- } \\
\text { des de universidades. }\end{array}$ \\
\hline
\end{tabular}

Fonte: os autores.

É preciso ressaltar que, para a análise dessas dimensões, foi necessário considerar que as ações institucionais trazem imbricadas em seu bojo uma gama de preceitos e valores relacionados ao contexto histórico, político e social de cada IES.

Revelam elas posições produzidas a partir de suas origens e motivações, com compromissos semelhantes, mas com ênfases próprias, relativas ao momento que vivem. Produzem discursos e apontam práticas que correspondem à orientação e culturas situadas.

É interessante considerar que o processo de internacionalização traz, em certos casos, um traço de imposição cultural, dando seguimento ao processo de colonização cultural; entretanto, se esse fenômeno da internacionalização é inevitável, que se extraiam daqueles que há mais tempo o implementam os resultados positivos e que se elimine o que não resulta em contribuição à sociedade e à comunidade acadêmica.

\section{FINALIZANDO: PERCEPÇÕES A PARTIR DA PESQUISA}

Salvaguardando a ideia que toda ação traz em seu bojo uma gama de valores e princípios relacionados ao contexto histórico, político e institucional, buscamos compreender as concepções e movimentos de duas Universidades situadas no Extremo-Sul do País em relação ao processo de internacionalização, procurando evidenciar 
as aproximações e os distanciamentos nos discursos que configuram as estratégias e ações para implementar esse processo.

Interessante perceber que, mesmo com algumas dificuldades, há empenho por parte da gestão das Universidades em promover discussões que contemplem a internacionalização como uma política institucional.

Reconhecem a necessidade de incorporar em seus Projetos de Desenvolvimento Institucional e Projetos Pedagógicos aspectos ligados à internacionalização. Contudo, apenas a Ub, universidade ainda em processo de consolidação, afirmou ter referências sobre a concepção de internacionalização no PDI. Entretanto, tornou-se claro que entender o que significa internacionalizar é condição essencial nesse movimento para que se possa contemplar a internacionalização nos projetos institucionais, sendo que ambas possuem na sua estrutura uma coordenadoria para tratar desses assuntos. Foram apresentadas algumas ideias sobre a internacionalização que merecem mais discussões no âmbito da comunidade acadêmica, sob o risco de esse processo ser entendido como restrito à mobilidade acadêmica. Não basta somente atender à demanda dessa mobilidade, é preciso planejar ações para a internacionalização acontecer na Universidade como um todo. Internacionalizar passou a ser uma condição necessária às IES, conforme apontaram nossos interlocutores.

É preciso empenho da gestão acadêmica no sentido de proporcionar intercâmbios e projetos de cooperação também com países da América Latina. A Ua demonstrou interesse na perspectiva de possibilitar acordos com a América Latina, situação não identificada na Ub, que enfatiza acordos com os EUA e Europa, apesar de ser uma universidade localizada em cidade de fronteira. São parcerias possíveis que podem fortalecer o ensino superior no Brasil e nos países do Mercosul. Parece ser uma possibilidade para esse contexto "sulino", além de alcançar o desenvolvimento regional diante da formação qualificada dos profissionais e poder competir no mercado cada vez mais seletivo.

A concepção de internacionalização passa pela perspectiva dos acordos nacionais e internacionais, incluindo a participação de alunos em programas de mobilidade estudantil e pela capacitação de professores para ministrar aulas em inglês. Entretanto, foi possível observar um expressivo interesse dos gestores em relação ao significado desse processo mais amplo de internacionalização no contexto do ensino superior.

Interessante perceber que o envolvimento das Universidades com o crescimento do espaço onde estão inseridas é fato considerado pela gestão como importante no processo de internacionalização. Essa é uma ideia afinada com os estudos sobre internacionalização os quais expõem que esse processo é impulsionado por uma 
avaliação das necessidades e prioridades individuais das instituições, considerando o reconhecimento local e regional da universidade. Há expectativa que o processo de internacionalização alimente as universidades no sentido de elas responderem às demandas regionais, na relação local-universal.

Constatamos, ainda, que as Instituições reconhecem e valorizam as experiências acadêmicas vividas por docentes e estudantes em outros lugares. No entanto, ainda não conseguiram potencializá-las nos currículos e nas práticas pedagógicas. Percebe-se que toda iniciativa de pensar os currículos e a forma de incorporar neles as experiências acadêmicas de mobilidade podem contribuir para consolidar o conceito de internacionalização nas Universidades.

Considerar o olhar dos gestores se constituiu em uma ação significativa para aprofundar e fazer avançar a discussão sobre a internacionalização do ensino superior. Esperamos que os resultados deste estudo sinalizem a importância da compreensão dessa temática complexa no contexto acadêmico contemporâneo.

Há necessidade de reflexão constante para proporcionar caminhos possíveis para a internacionalização na perspectiva da emancipação.

\section{REFERÊNCIAS}

ALTBACH, P. Comparative Higher Education: knowledge, the university, and development. Greenwich: Ablex, 1998.

ALTBACH, P. Globalization and the university: myths and realities in unequal world. Tertiary Education and Management, v. 10, i. 1, p. 3-25, Mar. 2004.

BARTELL, M. Internationalization of universities. A university culture-based framework. Higher Education, Manitoba, Winnipeg, v. 45, i. 1, p. 43-70, Jan. 2003.

CASTRO, A. A.; NETO, A. C. O ensino superior: a mobilidade estudantil como estratégia de internacionalização na América Latina. Revista Lusófona de Educação, v. 21, n. 21, 2012.

\section{GACEL-ÁVILA, J. Internacionalización de la Educación Superior en Améri-} ca Latina y el Caribe: reflexiones y lineamientos. Guadalajara: Ford Foundation, 1999.

KNIGHT, J. Five miths about Internationalization. International Higher Education, Chestnut Hill, n. 62, p. 14-15, 2011. 
KNIGHT, J. Internationalization Remodeled: definition, approaches, and rationales. Journal of Studies in International Education, Thousand Oaks, v. 8, i. 1, Mar. 2004.

KNIGHT, J. Universidades apostam na internacionalização. Jornal Extra Classe, Porto Alegre, 09 jul. 2014. Entrevista concedida a Grazieli Gotardo.

MOROSINI, M. C. Estado do conhecimento sobre internacionalização da educação superior: conceitos e práticas. Educar, Curitiba, n. 28, p. 107-124, 2006.

MOROSINI, M. C. Internacionalização na produção de conhecimento em IES brasileiras: cooperação internacional tradicional e cooperação internacional horizontal. Educação em Revista, Belo Horizonte, v. 27, n. 1, p. 93-112, 2011.

OLIVEIRA, A. R. M.; MOROSINI, M. C. Cooperação Internacional e Equidade: Será possível? Inter-ação, Goiânia, v. 38, n. 2, 2012.

SEIXAS, A. M. Políticas educativas para o ensino superior: a globalização neoliberal e a emergência de novas formas de regulação estatal. In: STOER, S. R. et al. (Org.). A transnacionalização da educação: da crise da educação à educação da crise. Porto: Afrontamento, 2001.

SOUSA SANTOS, B. de (Org.). A Globalização e as Ciências Sociais. 4. ed. São Paulo: Cortez Editora, 2011.

TEICHLER, U. The changing debate on internationalisation of higher education. Higher Education, v. 48, i. 1, p. 5-26, July 2004.

VAIRA, M. Globalization and higher education organizational change: a framework for analysis. Higher Education, v. 48, i. 4, p. 483-510, Dec. 2004.

Recebido em: 23 de maio de 2017

Aceito em: 09 de agosto de 2017

Endereço para correspondência: Cel. Alberto Rosa, Várzea do Porto, 96010-770, Pelotas, Rio Grande do Sul, Brasil; biazanchet@gmail.com 